\title{
A GRATUidade do ENSino PÚblico: COMO A QUESTÃo do ENSINO PÚBLICO SE APRESENTA NO DOCUMENTO FINAL DO PNE 2014-2024
}

\section{THE FREE EDUCATION AUDIENCE: AS THE QUESTION OF PUBLIC EDUCATION PRESENTS THE FINAL DOCUMENT OF PNE 2014-2024}

\author{
Maria Josélia Zanlorenzi ${ }^{1}$ \\ Michelle Fernandes Lima²
}

\section{RESUMO}

O presente texto trata da presença do setor privado na redação do Plano Nacional de Educação 2014-2024. Para compreender tal afirmação, partimos da análise de alguns conceitos que se apresentam no PNE, tais como: público e privado; administração pública gerencial, eficiência, eficácia, descentralização de responsabilidades e participação da sociedade na educação. Finalizamos o texto abordando a questão das consequências do setor privado na formação do indivíduo, o qual passa a receber uma formação individualista, com ênfase para a lógica do mercado, que atenda e estimule a competitividade, considerando, pois que a educação neste cenário, bem como a escola, mais uma vez é vista pela lógica capitalista como espaço de lucro.

PALAVRAS-CHAVE: Educação - Políticas Educacionais - Plano Nacional de Educação 2014-2024 - Relação Público-Privado na Educação.

\begin{abstract}
This paper deals with the presence of the private sector in the drafting of the National Education Plan 2014-2024. To understand this statement, we start the analysis of some concepts that are presented in the PNE, such as public and private; managerial public administration, efficiency, effectiveness, decentralization of responsibilities and participation of society in education. We finalized the text addressing the issue of private sector consequences in shaping the individual, which now receive an individualistic training, with emphasis on the logic of the market that meets and stimulate competitiveness.
\end{abstract}


KEYWORDS: Education - Educational Policy - National Education Plan 2014-2024 Public-Private Relationship in Education.

\section{INTRODUÇÃO}

Diante de tantos percalços que assolam a educação no Brasil, pretendemos no presente texto refletir sobre uma das polêmicas sobre as políticas educacionais brasileira na atualidade: o Plano Nacional de Educação (PNE) aprovado recentemente. As questões que se abrem para análise do documento do PNE 2014-2024, são inúmeras, perpassam a questão do financiamento, dos limites postos pela realidade escolar diante das metas a que o governo se propõe alcançar e até mesmo o tempo estipulado em dez anos para realizar as mudanças delineadas nesse Plano.

Bem sabemos da importância de conhecer e analisar os elementos que se apresentam como limites à concretização do Plano, porém nosso propósito no presente texto é discutir como se apresentam no novo Plano Nacional de Educação 2014-2024, os conceitos "público e privado" e como estes são tratados pelo atual PNE.

Diante das alterações e influências que sofrera a educação brasileira, ou seja, falamos das alterações no mundo do trabalho e dos acontecimentos em nível mundial os quais se refletem nas reformas educacionais orientadas pelos organismos internacionais. Quanto as influências, sobre as políticas educacionais na atualidade, temos que considerar a ideologia, valores, racionalidade e os interesses dos sujeitos que realizam as alterações e quais são suas perspectivas em relação às mudanças realizadas.

Segundo Shiroma, Campos e Garcia (2005) a legitimação de uma política altera as organizações escolares e as relações travadas em seu interior. Para entender as determinações trazidas em cada documento, as relações que determinam as mudanças, torna-se necessário interpretá-las relacionando os jogos políticos do campo da educação com outros setores que participam ativamente das decisões políticas de cada país. Entender seu conteúdo, os mecanismos envolvidos, conhecer a analisar os conceitos trazidos em todos os documentos, bem como o discurso que permeia os textos torna-se fundamental, visto que sua intencionalidade "[...] parece contraditória, fomentado medidas que aparentam ir em direção contrária ao que propõem" (SHIROMA; CAMPOS; GARCIA, 2005, p. 431). 
Temos por finalidade no presente estudo discutir a relação público-privado no documento "Plano Nacional de Educação" com vigência entre 2014-2024, na busca de conhecer como se apresenta a relação dos mencionados conceitos que permeiam as metas e estratégias do PNE e o papel do Estado no que se refere a educação pública brasileira. Para atender tais finalidades buscamos responder as seguintes questões: Como se dá a articulação entre o público e o privado na educação? Como acontece a interferência do privado no público nas escolas e quais suas consequências?

Para atender a este objetivo, o presente texto está organizado em dois momentos: no primeiro, discutimos a questão da privatização do ensino público na educação brasileira; no segundo, analisamos o documento final do Plano Nacional de Educação e a gratuidade do ensino público no atual documento. Por fim, apresentamos algumas reflexões sobre a influência e inserção da iniciativa privada no ensino público, fazendo deste último uma mercadoria, atendendo a lógica do mercado e a reformulação do Estado ocorrida do final do século XX.

A intenção de discussão sobre a temática público-privado partiu primeiramente da entrevista dada pela estudiosa em Políticas Educacionais Lisete Regina Gomes Arelaro ${ }^{3}$ a qual fez apontamentos sobre os conceitos contidos no atual Plano Nacional de Educação PNE 2014-2024, aprovado em maio de 2014.

Para compreendermos com maior profundidade tais conceitos, bem como a amplitude que os mesmos abrangem dentro das políticas educacionais, necessário se faz conhecer primeiramente como se dá a parceria público-privado na educação brasileira na atualidade e sua consolidação na legislação brasileira: Constituição Federal de 1988 e Lei de Diretrizes e Base da Educação Nacional LDBEN 9.394/96.

$\mathrm{Na}$ sequência, consideramos também ser de fundamental importância compreender o contexto das mudanças ocorridas a partir da década de 1990 no Brasil. Período em que a educação passou por profundas reformas, influenciada pelas alterações capitalistas e direcionadas pelos organismos internacionais, os quais objetivaram a redefinição do papel do Estado, reduzindo sua atuação quanto a responsabilidade da oferta das políticas sociais, a exemplo da educação.

No cenário brasileiro, a crise econômica levou a análise do fator determinante para o acontecimento da mesma, identificando-se o Estado como o principal responsável diante a globalização econômica. Acontecimento que levou a organização do Plano Diretor o qual direcionou a busca de soluções para construir novas alternativas pautadas em bases 
modernas e racionais de administração pública. Sugeriu este documento um "novo sentido" para a administração pública, chamando-a de "gerencial", espaço em que o público perde forças e passa a ser substituído pelo privado.

Compreendemos o conceito "público" enquanto o que é estatal, subsidiado com recurso público, com tributos pagos pelos brasileiros oriundos de impostos, contribuições e taxas. Verbas que financiam a educação pública e que oferece serviço gratuito ao povo e para o povo e sob a responsabilidade administrativa do Estado sendo, pois conhecidas como instituições estatais. "Público" tem seu significado "[...] o que é comum, pertence a todos, é do povo, pelo que, opondo-se ao privado, se mostra que não pertence nem se refere ao indivíduo ou ao particular" (SILVA, 2000, p. 661).

A questão do "público" na atualidade, sob a ótica de Luiz Carlos Bresser-Pereira e Nuria Cunill Grau (1999), apresenta-se sob duas modalidades: o público estatal e o público não estatal. O público estatal denominado pelos estudiosos Bresser Pereira e Cunill $\mathrm{Grau}^{4}$ de Estado Social-Burocrático; social pelo fato de no século XX assegurar os direitos sociais e o desenvolvimento econômico; burocrático por prestar este serviço por meio da utilização de servidores públicos, a exemplo da educação (BRESSER PEREIRA; GRAU, 1999).

O público não-estatal é apresentado no Plano Diretor da Reforma do Aparelho do Estado - PDRAE (1995) como a busca da superação da crise do Estado Social-Burocrático para o século XXI. Momento histórico em que o discurso neoliberal apresenta a justificativa de novas modalidades de administração pública aplicando os conceitos da eficácia, eficiência, administração pública gerencial, descentralização de responsabilidades e participação da sociedade.

Necessidade que visa a reforma do Estado tendo como alternativa a diminuição de sua atuação e transferência de suas responsabilidades ao setor privado. É apresentada como uma nova modalidade de administração pública sem ser estatal, nas palavras de Bresser Pereira: “[...] cresce a importância de uma forma não privada nem estatal de executar os serviços sociais garantidos pelo Estado" (BRESSER PEREIRA \& GRAU, 1999, p. 16). Justificativa que se mostra no discurso que o não estatal atende ao interesse público, ou seja, não tenha fins lucrativos e tem na Constituição Federal de 1988, em seu artigo 213 a definição de escolas sem fim lucrativos, definidas como as escolas comunitárias, confessionais ou filantrópicas.

Ainda citando a Constituição Federal de 1988, agora utilizando o capítulo, o qual trata da educação, ao articular os artigos 205, 209 e 213 entre si, Cury apresenta seu 
entendimento da seguinte forma: “[...] entendo que a nova Constituição estabelece dois gêneros de escolas: as públicas e as privadas. Já estas últimas se subdividem em duas espécies as lucrativas e as não lucrativas" (CURY, p. 35-36, 1992).

A questão do público e privado na Carta Magna de 1988 tem seu delineamento no Artigo 206, parágrafo $3^{\circ}$, o qual define que o ensino será ministrado com base no “[...] pluralismo de ideias e de concepções pedagógicas e coexistência de instituições públicas e privadas de ensino" (Brasil, 1988). Tendo a iniciativa privada assegurada sua ação na livre oferta de ensino no artigo 209: “O ensino é livre à iniciativa privada, atendidas as seguintes condições: I - cumprimento das normas gerais da educação nacional; II - autorização e avaliação de qualidade pelo Poder Público" (BRASIL, 1988).

Abre-se espaço para o favorecimento da inserção do setor privado na oferta de ensino com caráter publico. Isso acontece quando as escolas do setor privado atendem as mesmas normas atribuídas pelo Poder Público, no que concerne a autorização, funcionamento, e qualidade do ensino.

Porém, foi na atuação do então Ministro da Modernização Administrativa e Reforma do Estado, Luiz Carlos Bresser Pereira, pela Emenda Constitucional n. 19 de 4 de junho de 1998, em seu teor "Modifica o regime e dispõe sobre princípios e normas da Administração Pública [...]” (BRASIL, 1998).

Consolidaram-se os princípios de público não-estatal e o gerenciamento do setor público pela iniciativa privada por meio de contratos entre a administração pública e empresas que prestam assessoria no gerenciamento do serviço público. No artigo $3^{\circ}$, inciso $8^{\circ}$ do mencionado documento, tomam forma na administração da educação brasileira os conceitos de "eficiência" e "metas de desempenho" estabelecidas conforme o interesse do contratado:

\footnotetext{
A autonomia gerencial, orçamentária e financeira dos órgãos e entidades da administração direta e indireta poderá ser ampliada mediante contrato, a ser firmado entre seus administradores e o poder público, que tenha por objeto a fixação de metas de desempenho para o órgão ou entidade (BRASIL, EMENDA CONSTITUCIONAL N. 19, 1998).
}

A administração pública no setor educacional brasileiro sofre alterações frente ao discurso neoliberal da ineficiência da ação do Estado Social-Burocrático, as quais se manifestam de forma mais evidente na questão do público não-estatal. Situação em que o Estado se exime de sua responsabilidade em executar as políticas sociais, a exemplo da 
educação como direito inalienável do cidadão e dever do Estado. O que continua sobre sua responsabilidade passa a atender a lógica do mercado seguindo sua forma de gestão, avaliação, administração gerencial e da competitividade. Dessa forma o Estado exerce apenas o controle da execução e resultados das políticas sociais:

\footnotetext{
O papel do Estado para com as políticas sociais é alterado, pois com este diagnóstico duas são as prescrições: racionalizar recursos e esvaziar o poder das instituições, já que instituições democráticas são permeáveis às pressões e demandas da população, além de serem consideradas como improdutivas, pela lógica de mercado. Assim, a responsabilidade pela execução das políticas sociais deve ser repassada para a sociedade: para os neoliberais por meio da privatização (mercado), e para a Terceira Via pelo público não-estatal (sem fins lucrativos) (PERONI, 2006, p.14, grifos do autor).
}

A responsabilidade administrativa da educação pública nacional toma forma gerencial de empresa. Para facilitar a ação da iniciativa privada no ensino brasileiro, uma das primeiras ações do Estado, legalizada na Constituição Federal de 1988, foi a descentralização das responsabilidades, em que a União, os Estados e Municípios, em regime de colaboração entre estas esferas atuam na administração da educação. Cada ente federado responsabiliza-se pela oferta da etapa ou nível da educação definida à sua competência pelas bases legais, porém gerenciada e avaliada pela União.

Delineamentos de administração que enfatizam o caráter privatista da reforma de 1990 encaminhadas pelo governo por meio das leis que regem a educação brasileira na atualidade. Ações que direcionam e concretizam cada vez mais a inserção da rede privada no sistema público de ensino reafirmando-se na recente aprovação do Plano Nacional de Educação PNE 2014- 2024.

\section{O PÚblico E PRiVAdo no ATUAL Plano NACIONAL de EdUCAÇÃo 2014- 2024}

Já no início de sua redação, o PNE 2014-2024 apresenta em forma de esclarecimento que o mesmo foi elaborado partindo de um diagnóstico da educação nacional, bem como das expectativas da sociedade quanto às desejadas mudanças na educação brasileira, isso em vista ao alcance da qualidade do ensino oferecido em contexto nacional. 
Movidos por esta intenção e objetivo, houve em todo o território nacional organizações, movimentos e conferências, a exemplo da Conferência Nacional de Educação, a CONAE, realizada em 2010, que contou com a participação de diversos seguimentos da sociedade brasileira com o objetivo de elaborar e apresentar subsídios para a organização de um plano que realmente trouxesse para a educação as melhorias desejadas.

Sugestões e documentos elaborados que partiram de estudos e experiências daqueles que estão realmente inseridos na realidade da educação. Conhecem as reais necessidades e problemas do ensino no Brasil e apontam com conhecimento de causa e propriedade as possíveis soluções ou contribuições para a melhoria da educação no Brasil. Na tramitação das propostas sobre o PNE 2014-2024, o Projeto de Lei (PL n. 8.035), entregue pelo governo ao Congresso Nacional em dezembro de 2010 não atendeu as decisões da CONAE e representantes dos movimentos que se organizaram para a elaboração das propostas. Ação que comprometeu o esforço da elaboração do documento, e “[...] resultado dos debates e disputas internas ocorridos no espaço democrático de discussão que esta possibilitou, não foram, em sua maioria, contemplados no PL 8.035/2010" (OLIVEIRA, et all., 2011, p. 484).

O Plano Nacional de Educação (PNE) foi sancionado pela presidenta Dilma Roussef e define os rumos da educação brasileira de 2014 a 2024. A Lei $n^{\circ} 13.005$ de 25 junho de 2014 pela qual se aprovou o Plano Nacional de Educação também institui, o Fórum Nacional de Educação (FNE) para que aconteça o "alinhamento" dos Planos entre as esferas Estaduais, Distrital e Municipais de Educação, objetivando que os mesmos sejam elaborados em consonância com o Plano Nacional de Educação vigente.

De forma dissimulada, o Plano Nacional de Educação reforça em seu conteúdo, mais uma vez, a privatização do ensino público. Podemos observar na letra do próprio PNE 2014-2024, Artigo 5 , parágrafo $4^{\circ}$ da Lei n. 13.005 de 25 de junho de 2014, a consolidação não só da influência, mas da inserção e transferência do ensino público para o setor privado por meio de programas de financiamento estudantil de diferentes formas e nas diferentes etapas e modalidades da educação brasileira:

$\S 4^{\circ}$ : O investimento público em educação a que se refere o inciso VI do art. 214 da Constituição Federal e a meta 20 do anexo desta Lei engloba os recursos aplicados na forma do art. 212 da Constituição Federal e do art. 60 do Ato das Disposições Constitucionais Transitórias bem como os recursos aplicados nos programas de expansão de educação profissional e superior, inclusive na forma de incentivo e isenção fiscal, as bolsas de estudos concedidas no Brasil e no exterior, os subsídios concedidos em programas de financiamento estudantil e o financiamento de creches, 
pré-escolas e educação especial na forma do art. 213 da Constituição Federal (BRASIL, 2014, grifos no original).

Legalizada a forma como acontecerá a privatização do ensino público brasileiro, nas metas e estratégias que compõem o Plano Nacional de Educação 2014-2024, estas visam materializar o que fora planejado pelo governo, no que concerne a política de redefinição do papel do Estado e redução de sua participação na responsabilidade da oferta e manutenção das políticas públicas.

Podemos ainda observar nas metas 11 e 12, em que o texto do Plano expressa as intenções do governo em triplicar as matrículas do ensino médio profissional e assegurar pelo menos $50 \%$ de gratuidade de expansão de vagas. Na meta 12, pretende-se assegurar a oferta de pelo menos $40 \%$ das novas matrículas no ensino público. Embora demasiada extensa, apresentamos na sequência algumas das estratégias que confirmam o investimento de recursos públicos no setor privado:

11.6 Ampliar a oferta de matrículas gratuitas de educação profissional técnica de nível médio pelas entidades privadas de formação profissional vinculadas ao sistema sindical e entidades sem fins lucrativos de atendimento à pessoa com deficiência, com atuação exclusiva na modalidade.

11.7 Expandir a oferta de financiamento estudantil à educação profissional técnica de nível médio oferecida em instituições privadas de educação superior.

11.9 expandir o atendimento do ensino médio gratuito integrado á formação profissional para as populações do campo e para as comunidades indígenas e quilombolas, de acordo com os seus interesses e necessidades;

12.5 ampliar as políticas de inclusão e de assistência estudantil dirigidas aos (às) estudantes de instituições públicas, bolsistas de instituições privadas de educação superior e beneficiários do Fundo de Financiamento Estudantil - FIES, deque trata a lei n. 10.260, de 12 de julho de 2001, na educação superior [...] (BRASIL, 2014).

Utiliza-se de um jogo de palavras em que a transferência da responsabilidade da educação brasileira passa a ser administrada pelo setor empresarial sem a percepção, ou sem ser apresentada de forma clara aos interessados. Faz-se uso dos termos: "matrículas gratuitas", "financiamento estudantil" e "ensino gratuito" como meio de não transparecer a aplicação do dinheiro público em empresas que oferecem serviços ao Estado na forma de parcerias e intervenção na gestão administrativa.

A forma encontrada pelo Estado em desincumbir-se de sua função de oferecer e manter as políticas sociais em termos de educação foi passar para o setor privado a oferta do 
ensino, assegurando essa transferência no PNE. Esta será mantida com dinheiro público, mas com administração do privado. O empresariado passa a gerenciar os recursos públicos destinado à educação por meio da parceria público-privado e da proposta de publicização do ensino, entrando em cena o público não-estatal.

O Plano Nacional de Educação, estabelecido como Lei, vem a ser um Plano de governo que efetiva na educação, as mudanças apontadas por Bresser Pereira e a reforma do Estado. As soluções apontadas por Bresser Pereira (1999) foi a superação do papel do Estado o qual deixa de concentrar e centralizar funções e adota o modelo gerencial. Bresser Pereira (1999) defende a necessidade de aperfeiçoar a gestão do Estado e para isso adota mecanismos que criam novas formas de relacionamento entre Estado e sociedade civil.

A forma como se insere a intervenção do empresariado na administração pública, segundo o Plano Diretor da Reforma do Aparelho do Estado PDRAE (1995) acontece pela articulação entre o estatal e o privado, que tem como resultado uma nova forma na gestão das políticas públicas. Como já foi afirmado anteriormente, é substituída a administração pública burocrática pela administração pública gerencial que segue as regras do mercado.

\begin{abstract}
As estratégias apontadas pelo Plano são: a privatização, a publicização e a terceirização. Terceirização, conforme Bresser Pereira, é o processo de transferência para o setor privado dos serviços auxiliares ou de apoio. A publicização consiste "na transferência para o setor público não-estatal dos serviços sociais e científicos que hoje o Estado presta"(PEREIRA, 1997, p. 7). E a privatização consiste no repasse para o setor privado das atividades lucrativas. O Plano propõe ainda a gestão gerencial, visando ao atendimento do cidadão cliente (PERONI, 2006, p 8).
\end{abstract}

A administração pública gerencial pauta-se na descentralização política e administrativa que transfere recursos, atribuições e autoridade para os administradores públicos locais e regionais; estabelece objetivos a serem atingidos pelas unidades descentralizadas e medidos, a posteriori por meio de indicadores de desempenho o qual visa controle de resultados. Estratégia utilizada pelo Estado, por meio de parceria entre Estado e Sociedade (Bresser Pereira, 1999). É a oferta de serviços não exclusivos do Estado, que acontecem por meio das políticas de privatização e descentralização, oferecidas por Organizações Públicas não Estatais (OPNES).

Nesse contexto de Reforma do Estado, uma das formas de concretizar o público não estatal é a existência do Terceiro Setor na execução das políticas sociais. Sua ação acontece por meio das Organizações Sociais (OS) e das Organizações da Sociedade Civil de 
Interesse Público (OSCIPs). O Terceiro Setor desempenha atividades de interesse público pautado em contratos de gestão com o governo e assegurado pela Lei $n^{\circ} 9.637$, de 15 de Maio de 1998, que cria o Programa de Publicização e define e estabelece as formas de atuação e qualificação das entidades das Organizações Sociais:

\begin{abstract}
Art. $1^{0} \mathrm{O}$ Poder Executivo poderá qualificar como organizações sociais pessoas jurídicas de direito privado, sem fins lucrativos, cujas atividades sejam dirigidas ao ensino, à pesquisa científica, ao desenvolvimento tecnológico, à proteção e preservação do meio ambiente, à cultura e à saúde, atendidos aos requisitos previstos nesta Lei (BRASIL, Lei n 9.637, de 15 de Maio de 1998).
\end{abstract}

O próprio PNE, no art. $8^{\circ}$, parágrafo $2^{\circ}$ ressalta a participação da sociedade civil na elaboração dos planos nos diferentes entes federados:

Os processos de elaboração e adequação dos planos de educação dos Estados, do Distrito Federal e dos Municípios, de que trata o caput deste artigo, serão realizados com ampla participação de representantes da comunidade educacional e da sociedade civil (BRASIL, 2014).

Segundo Bresser Pereira e Grau (1999) para se efetivar essa nova forma de gestão é necessário que se constitua um espaço público não estatal, denominado pelos mesmos de Terceiro Setor, "setor sem fins lucrativos" ou "setor não governamental" engendrado como modo nem estatal nem privado de executar as políticas sociais que competem ao Estado.

Para este fim, uma das formas encontradas para que acontecesse a administração da educação sem a participação direta do Estado foi trazer a sociedade civil para participar do gerenciamento da educação.

A participação da sociedade civil, acompanhada pelo discurso de "gestão democrática" permitida por um Estado "democrático" transfere o que seria de sua responsabilidade à sociedade civil, ocorreu uma "entronização" da sociedade, que de forma pragmática foi reduzida a um recurso gerencial (NOGUEIRA, 2005).

Salientamos que a participação da sociedade civil organizada em defesa da educação pública, no que concerne a elaboração das políticas sociais e decisões que realmente mudem a realidade em que se apresenta a educação brasileira fica somente na elaboração e apresentação de propostas e planos. Esses, ao efetivarem-se enquanto lei sofrem profundas 
alterações até que atendam aos interesses dos governantes, a exemplo do documento da CONAE 2010 e do próprio PNE 2014-2024. Vale lembrar uma vez mais que o mesmo ocorreu com a discussão do Projeto de Lei da atual LDBEN 9.394/96 5 .

Em se tratar do atual PNE 2014-2024, a utilização dos termos que remetem a transferência de responsabilidade do governo para o setor privado, muda conforme a meta e estratégia. Para expressar a relação entre público e privado, utiliza-se ainda os termos "parceria" "colaboração" "articulação" "conveniadas" a exemplo da meta 4, estratégia 4.1 e das metas 11, estratégias $11.6,11.7,11.9$ e 12, estratégia 12.5 acima mencionadas as quais abordam a questão da privatização dissimulada do ensino, não perdendo o sentido de transferência que desincumbe o Estado do seu papel de provedor na oferta, financiamento e implementação da educação.

Por meio da Constituição Federal de 1988, foi então desenhado um novo quadro de responsabilidades educacionais, que alterou tanto o arranjo federativo do país quanto as relações entre o Estado, o setor privado lucrativo e não lucrativo na oferta e distribuição de educação escolar (BONAMINO, 2003, p. 528).

Seguindo a ordem da reforma do Estado, outro mecanismo encontrado pelo governo federal desincumbir-se da manutenção da educação pública ocorreu pelo regime de colaboração entre os entes federados. O mecanismo de centralização e descentralização financeira, administrativa e pedagógica estabelecida pelo termo "colaboração" entre os entes federados: União, Estados, Distrito Federal e Municípios posto pela Constituição Federal (1988) possibilitou aos governadores e prefeitos a expansão de sua autoridade em relação aos recursos fiscais e na gestão e elaboração de políticas públicas (BONAMINO, 2003).

A possibilidade dos municípios elaborarem suas próprias políticas públicas possibilitou a infiltração da lógica gerencial na educação. Isso se reflete com maior evidência na educação de diferentes formas: as propostas de gestão e de currículo que afetam diretamente na formação dos alunos do ensino público, o repasse do dinheiro público ao setor privado, a interferência do setor privado na elaboração de políticas públicas, na formação de professores e na oferta de vagas com subvenção pública principalmente na Educação Infantil.

Pela Meta 1, estratégia 1.7 pretende-se "Articular a oferta de matrículas gratuitas em creches certificadas como entidades beneficentes de assistência social na área de educação com a expansão de oferta na rede escolar pública"(Brasil, 2014). Acontece por meio desse 
mecanismo a subvenção pública aos estabelecimentos privados que se concretizam de distintas formas "[...] cessão de prédio público, pagamento de profissionais contratados pela instituição privada com recurso público e merenda etc.”, (ADRIÃO, BORGHI, DOMICIANO, 2010, p. 290).

O fato da descentralização da oferta de ensino atribuída a cada uma das esferas federativas levou os municípios a buscarem alternativas para atender as etapas de ensino que lhe cabem. Segundo Adrião (2009), o setor privado, representado por sistemas de ensino a exemplo do Grupo Positivo, Sistema de Ensino Osvaldo Cruz atuam em forma de "parcerias" com as prefeituras oferecendo seus produtos em forma de "pacotes" que de início é a adoção do sistema de apostilas para se trabalhar com os alunos.

$\mathrm{Na}$ sequência da parceria selada entre as partes interessadas, conta-se com assessorias na elaboração, orientação e organização de políticas educacionais locais e de modelos de gestão das instituições por parte do contratado. A esse respeito são pertinentes as observações de Adrião, Garcia, Borghi, \& Arelaro (2009):

\begin{abstract}
Acreditamos, também, que a análise das relações entre os setores público e privado não pode se limitar à sua caracterização jurídica, ainda que este aspecto não deva ser negligenciado. É o conjunto de responsabilidades compartilhadas ou transferidas do setor público para a instituição privada, bem como a centralidade das atividades previstas nesta transferência para a consecução de políticas públicas que consubstanciam a natureza da parceria. Por esse motivo, no caso aqui destacado, acredita-se que, para além de mera aquisição de apostilas ou cursos pelos governos municipais, trata-se da transferência para a esfera privada da função de elaboração e operacionalização de política pública até então exercida pela esfera pública estatal (ADRIÃO, GARCIA, BORGHI \& ARELARO, 2009, p. 802).
\end{abstract}

A adoção de parcerias entre prefeituras e o setor privado, na forma de assessoria não implica somente no uso de materiais didáticos, mas altera significativamente a forma de organização e as ações das instituições educativas que recebem a intervenção das empresas que oferecem assistência. Isso se reflete diretamente no Projeto Político Pedagógico, na organização do trabalho na escola e na coordenação pedagógica (MIRALHA, SOARES, PINTO, MILITÃO, 2012).

As mudanças propostas pelos Grupos ou Sistemas de ensino que oferecem seus serviços aos municípios muda consideravelmente os objetivos de ensino e da função social da escola. Pautados em argumentos que seguem a lógica empresarial de gestão, organização e 
funcionamento, justificam suas ações de que o sistema público não conta com um sistema administrativo eficiente.

Seguir um padrão de organização e um sistema de avaliação de qualidade para medir o desempenho da instituição escolar e do ensino aprendizagem dos alunos é o caminho para quem deseja alcançar a excelência em qualidade, na ótica do ensino privado. Para alcançar tal finalidade instaura-se a lógica da "competência" expressa pelo planejamento, organização e ação, e por que não afirmar, da competitividade entre as instituições públicas.

Alcançar os objetivos propostos pelos Grupos e Sistemas de Ensino privado, implica em mudanças no currículo e na ação dos professores. Diante dos problemas enfrentados pelos municípios para atender os Anos Iniciais da Educação Básica trazido pela municipalização do ensino.

Para melhor explicitar a situação podemos apontar duas questões pontuais que se fazem presentes em boa parte dos municípios brasileiros - a precariedade técnico-operacional e a precariedade na formação de professores. Situação que leva a adoção pelos municípios da proposta de parceria com o setor privado; este apresenta propostas rápidas e precisas para ajustar e agilizar a organização e o trabalho nas escolas (ADRIÃO, GARCIA, BORGHI \& ARELARO, 2009).

A alternativa apresentada pelo setor privado é o treinamento para o setor administrativo para que se tenha um quadro técnico qualificado que dê suporte às instituições escolares e o apostilamento para o trabalho do professor. Ao delegar para o setor privado a administração dos procedimentos técnico-operacional e pedagógicos das redes de ensino, estas determinam o tempo de trabalho dos funcionários e professores, a rotina da equipe pedagógica e administrativa, a metodologia de ensino do professor e os conteúdos. Define ainda os conteúdos a serem desenvolvidos pelos professores, estabelece uma padronização do ensino com o discurso de evitar a desigualdade entre as escolas, o que ocasiona, além da alteração do currículo, o desrespeito às especificidades culturais, sociais e econômica de cada região (ADRIÃO, GARCIA, BORGHI \& ARELARO, 2009). Ainda nas palavras das mencionadas autoras:

A padronização, tendo em vista a qualidade, é justificada pelo gestor quando este reconhece, ou afirma assim ser, a incapacidade do município promover ações com vistas a qualificar o ensino e pressupõe a adoção de um único referencial pedagógico capaz de prever condutas, prescrever atividades e propor tempos unificados para o trato com o conteúdo. Neste caso, a recorrência ao sucesso do setor privado em atingir suas metas é o recurso apresentado. Não há menções às desigualdades sociais, culturais e econômicas existentes e às diferenças inevitáveis entre as escolas 
e seus atores: é a supervalorização dos meios, alienados de fins desejados. Estamos de volta ao tecnicismo dos anos de 1970, com a diferença de agora os meios mais eficazes e eficientes virem adjetivados: precisam ser privados (ADRIÃO, GARCIA, BORGHI \& ARELARO, 2009, p. 812).

A consequência da influência do setor privado no ensino público se manifesta na formação do indivíduo que frequenta a escola e recebe em sua formação a lógica do mercado, tendo em vista a qualidade, mas não a qualidade de ensino nem a formação do indivíduo, mas a "qualidade" exigida pelo mercado. Esta, inserida na educação pelas redes municipais, estipula e estimula a competitividade entre as escolas e os indivíduos, os quais recebem formação que atende aos padrões determinados pela lógica capitalista.

Atendendo a lógica capitalista, uma vez mais, a escola passa a ser um espaço permeado pela individualidade, pelo lucro, competitividade, que no caso das escolas é estimulada pelas notas do IDEB e entre os alunos, aquele que melhor se sai nas avaliações de ensino aprendizagem. Para atender este sistema submetem-se às condições de competição, desvinculado da realidade a que pertencem.

Desconhecem todo o mecanismo que rege e que determina o âmbito econômico e que define de forma precisa o conjunto de relações sociais e políticas, os quais refletem diretamente na escola. Mantendo-os distante de sua situação de explorado, inseridos em uma sociedade dividida em classes, mas que continua, por meio da própria escola, ao atender a lógica capitalista, em não oportunizar o conhecimento das relações que se dão na sociedade a que pertencem, reforçando sua condição de alienado.

\section{CONSIDERAÇÕES FINAIS}

Percebemos na redação do atual Plano Nacional de Educação a presença do encaminhamento para a privatização do ensino público brasileiro. Hora implícita, hora explícita, os delineamentos dados para a privatização da educação na atual conjuntura em que se encontra o cenário político brasileiro direcionam cada vez mais para a concretização do que fora estabelecido no PNE quanto as metas e estratégias citadas nas discussões apresentadas no presente texto.

Sabemos que entre uma política planejada e aprovada e sua consolidação, há muitos percalços e desafios para que esta ação tomada pelo governo se efetive realmente. 
Dentre os grandes desafios em se efetivar uma política pública, em específico na educação, apontamos as dificuldades que se apresentam em sua implementação, em termos de efetivação no interior da escola; as limitações de formação dos profissionais do magistério, organização ou até mesmo de condições de financiamento, quando se trata do regime de parceria entre os entes federados; as grandes diferenças e desigualdades regionais existentes no cenário brasileiro.

No entanto, ao olharmos os esforços tomados pelo governo no que concerne a educação, parece ser bem mais fácil, da parte dos governantes, tornar realidade o estabelecido no PNE para o direcionamento da privatização frente a qualquer outro esforço em concretizar as demais questões postas no Plano Nacional de Educação as quais visam a qualidade da educação. É urgente tomarmos atenção para os direcionamentos dados no Plano Nacional de Educação atual quanto aos encaminhamentos e aberturas dados para o setor privado, bem como para as consequências que tais ações planejadas conduzem o ensino público brasileiro.

Por fim, temos que nos ater para as tomadas de decisões governamentais, sobre o ensino público na atualidade: cortes de verbas, professores mal remunerados, escolas com seus espaços físicos sem condições de uso e professores sem condições de trabalho. Situação que leva a concretização do estabelecido no recente PNE quanto a privatização do ensino, que a nosso ver, são formas de justificar a decadência e a ineficiência da administração pública na educação.

\section{REFERÊNCIAS}

ADRIÃO, Theresa. Estratégias municipais para a oferta da educação básica: análise de parcerias público-privado no Estado de São Paulo. São Paulo: FAPESP, 2009.

ADRIÃO, Theresa; BORGHI, Raquel; DOMICIANO, Cassia Alessandra. Educação infantil, ensino fundamental: inúmeras tendências de privatização. Revista retratos da Escola, Brasília, v. 4, n. 7, p. 285-298, jul./dez. 2010. Disponível em: <http//www.esforce.org.br. Acesso em: 20 de dez. de 2014.

ADRIÃO, Theresa; GARCIA, Teise; BORGHI, Raquel; ARELARO, Lisete Regina Gomes. Uma modalidade peculiar de privatização da educação pública: a aquisição de "sistemas de 
ensino" por municípios paulistas. Revista Educação e Sociedade, Campinas, vol. 30, n. 108, p. 799-818, out. 2009. Disponível em: Disponível em http://www.cedes.unicamp.br. Acesso em: 12 de dez. de 2014.

ARELARO, Lisete Regina Gomes. Resistência e submissão: a reforma educacional na década de 1990. IN: KRAWCZYK, Nora; CAMPOS, Maria Marta; HADDAD, Sérgio. (Orgs.) O cenário educacional latino-americano no limiar do século XXI: reformas em debate. Campinas, SP: Autores Associados, 2000.

BRASIL. Constituição da República Federativa do Brasil, promulgada em 05 de outubro de 1988. Disponível em: http://www.planalto.gov.br/ccivil_03/constituicao/constituicao.htm. Acesso em: 29 de dez. de 2014.

Lei N. 13.005, de 25 de junho de 2014. Aprova o Plano Nacional de Educação e dá outras providências. Disponível em:http://www.planalto.gov.br/ccivil_03/_Ato20112014/2014/Lei/L13005.htm. Acesso em: 28 de dez. 2014.

Lei $\mathbf{n}^{0}$ 9.637, de 15 de maio de 1998. Dispõe sobre a qualificação de entidades como organizações sociais, a criação do Programa Nacional de Publicização, a extinção dos órgãos e entidades que menciona e a absorção de suas atividades por organizações sociais, e dá outras providências. Disponível em: http://www.planalto.gov.br/ccivil_03/leis/19637.htm. Acesso em: 22 de jan. de 2015.

BONAMINO, Alicia Maria Catalano de. O público e o privado na educação brasileira: inovações e tendências a partir dos nãos de 1980. Revista Brasileira de história da Educação n. 5 jan./jun. $2003 . \quad$ Disponível em: http://www.vdl.ufc.br/solar/aula_link/lquim/A_a_H/estrutura_pol_gest_educacional/aula_01/i magens/06/Publico_Privado_Na_Educacao_Brasileira_2.pdf. Acesso em: 30 de jan. de 2015.

BRESSER PEREIRA, Luiz. Carlos. \& GRAU, Nuria Cunill. Entre o Estado e o mercado: o público não-estatal. Disponível e: http://disciplinas.stoa.usp.br/pluginfile.php/192477/mod_resource/content/1/84PublicoNaoEst ataRefEst.p.pg.pdf. Acesso em: 02 de jan. de 2015. 
BRESSER PEREIRA, L.C. Uma reforma gerencial da administração pública no Brasil. IN: PETRUCCI,V. e SCHWARZ, L. Administração pública gerencial: a reforma de 1995. Brasília: Editora da Universidade de Brasília: ENAP, 1999.

CURY, Carlos Alberto Jamil. O público e o privado na educação brasileira contemporânea: posições e tendências. Cadernos de Pesquisa. São Paulo, n. 81, p. 33-44, maio de 1992. Disponível em: http://www.fcc.org.br/pesquisa/publicacoes/cp/arquivos/914.pdf. Acesso em: 27 de nov. de 2014.

NOGUEIRA, Marco Aurélio. Um Estado para a Sociedade Civil: temas éticos e políticos da gestão democrática. - 2. ed. - São Paulo: Cortez, 2005.

MIRALHA, Mayara Faria; SOARES Mariana Padovan Farah; PINTO Elba Geovana de Sousa; MILITÃO, Silvio Cesar Nunes. Sistemas apostilados de ensino: implantação e implicações sobre a docente. Disponível em:http://www.unoeste.br/site/enepe/2012/suplementos/area/Humanarum/Ci\%C3\%AAncias \%20Humanas/Educa\%C3\%A7\%C3\% A3o/SISTEMAS\%20APOSTILADOS\%20DE\%20ENS INO $\% 20 \% 20$ IMPLANTA\%C3\%87\%C3\%830\%20E\%20IMPLICA\%C3\%87\%C3\%95ES\%2 OSOBRE\%20A\%20AUTONOMIA\%20DOCENT\%20E.pdf. Acesso em: 15 de jan. de 2015.

OLIVEIRA, Dalila Andrade (et all). Por um Plano Nacional de Educação (2011-2020) como política de Estado. Revista brasileira de Educação. v. 16, n. 47. Maio de 2011. Disponível em: $\quad$ http://www.scielo.br/scielo.php?script=sci_issuetoc\&pid=1413247820110002\&lng=pt\&nrm=iso. Acesso em: 14 de dez. de 2014.

PERONI, Vera. Mudanças na configuração do Estado e sua influência na política educacional. In: PERONI, V. M. V., BAZZO, V. L. , PEGORARO, L. (org.) Dilemas da educação brasileira em tempos de globalização neoliberal: entre o público e o privado. Porto Alegre: Editora da UFRGS, 2006.

SILVA, De Plácido. Vocabulário jurídico. Rio de Janeiro: Forense, 2000. 
SHIROMA, Eneida Oto; CAMPOS, Roselane Fátima; GARCIA, Rosalba Maria Cardoso. Decifrar textos para compreender a política: subsídios teórico-metodológicos para análise de documentos. Perspectiva, Florianópolis, v. 23, n. 2, p. 427-446, jul./dez. 2005.

\footnotetext{
${ }^{1}$ Maria Josélia Zanlorenzi - E-mail: mjzanlorenzi@ hotmail.com Mestre em Educação pela Universidade Estadual de Ponta Grossa, UEPG na linha de pesquisa "História e Políticas Educacionais, professora do curso de Pedagogia na Universidade Estadual do Centro-Oeste UNICENTRO - Guarapuava-PR

${ }^{2}$ Michelle Fernandes Lima - E-mail: mfernandeslima@yahoo.com.br - Doutora em educação pelo Programa de Pós Graduação em Educação da UFPR. Professora do Programa de Pós Graduação em Educação da Universidade Estadual do Centro Oeste. Líder do grupo de pesquisa Estado, Politicas e Gestão da Educação na Universidade Estadual do Centro-Oeste-UNICENTRO/IRATI-PR

${ }^{3}$ A mencionada entrevista foi publicada em 28 de outubro de 2011 e encontra-se disponível no site: https://www.youtube.com/watch?v=4E1mMx9cP9o. Acesso em 31 de agosto 2016.

${ }^{4}$ Sugerimos a leitura de BRESSER PEREIRA, Luiz. Carlos. \& GRAU, Nuria Cunill. Entre o Estado e o mercado: o público não-estatal.

${ }^{5}$ Para maior esclarecimento sobre a elaboração da atual LDBEN 9.394/96 ler: Resistência e submissão: a reforma educacional na década de 1990 (ARELARO, 2000).
}

RECEBIDO EM: Setembro de 2016

APROVADO EM: Dezembro de 2016 